\title{
DOUBLE INTEGRAL INEQUALITIES BASED ON MULTI-BRANCH PEANO KERNELS
}

\begin{abstract}
A. SOFO
Abstract. The Ostrowski inequality in one dimension has been known for about seventy years. In the last two or three years an Ostrowski type inequality in two dimensions has been developed. In this paper we extend these ideas in two dimensions to obtain double integral inequalities that are based on multi-branch Peano kernels.
\end{abstract}

Mathematics subject classification (2000): 26D15, 41A55.

Key words and phrases: Ostrowski inequality, cubature formula.

\section{REFERENCES}

[1] A. OSTROWSKI, Über die Absolutabweichung einer differentiierbaren Funktion von ihrem Integralmittelwert, Comment. Math. Helv, 10 (1938), 226-227.

[2] S. S. DRAGOMIR, A generalization of Ostrowski integral inequality for mappings whose derivatives belong to $L_{\infty}[a, b]$ and applications in numerical integration, SUT J. Math., (accepted).

[3] S. S. DRAGOMIR, A generalization of Ostrowski integral inequality for mappings whose derivatives belong to $L_{1}[a, b]$ and applications in numerical integration, J. of Computational Analysis and Applications, (in press).

[4] S. S. DRAGOMIR, A generalization of Ostrowski integral inequality for mappings whose derivatives belong to $L_{p}[a, b], 1<p<\infty$, and applications in numerical integration, J. Math. Anal. Appl., (in press).

[5] S. S. DRAGOMIR, The Ostrowski's integral inequality for mappings of bounded variation, Bull. Austral. Math. Soc., 60 (1999), 495-508.

[6] A. Sofo, Integral inequalities for n-times differentiable mappings, Chapter 2, Ostrowski Type Inequalities and Applications in Numerical Integration, RGMIA Monographs, Victoria University, 2000. (Online: http://rgmia.vu.edu.au/monographs).

[7] N. S. BARNETT AND S. S. DRAGOMIR, An Ostrowski type inequality for Double Integrals and Application for Cubature formulae, submitted to Soochow J. of Math, 1999.

[8] S. S. DRAGOMIR, N. S. BARNETT AND P. CERONE, An Ostrowski type inequality for double integrals in terms of $L_{p}$ - Norms and applications in Numerical integrations, Anal. Num. Theor. Approx (Romania), (accepted).

[9] G. HANNA, S. S. DRAGOMIR AND P. CERONE, A general Ostrowski type inequality for double integrals, RGMIA Res. Rep. Coll., 3 (2), Article 10, 2000. (Online: http://rgmia.vu . edu .au/v2n3 .htm1). 